\title{
New Millennium, New Climate: What Role for the Restorationist?
}

As we move into the 21 st century, the phantoms of the past remain with us. The landscapes and ecosystems we inhabit, protect, and restore continue to reflect our past ideals, values, and lands use choices. Now comes the ominous realization that global climate patterns are becoming increasingly influenced by past and present human decisions. This, of course, is not news to environmentally-minded people (for example, long-time readers of RMN/ER may recall an article about climate change by Robert Peters in vol. 3 no. 2, 1985), but the picture is becoming more clear and more widely recognized by policymakers and the general public.

Reports earlier this year from the United Nations-sponsored Intergovernmental Panel on Climate Change and the recentlyreleased assessment by the U.S. Global Change Research Program both forecast a significantly different climate for the $21 \mathrm{st}$ century due to rising levels of humanly-produced greenhouse gases. If these predictions are true, we can expect sea levels to rise dramatically along the coasts, the loss of some plant communities, such as alpine meadows in the Rocky Mountains, and the break-up of other plant communities as species drift northward following the expected rise in temperature. Obviously such a change in climate has major implications throughout the world in terms of agriculture, water supply, fishing-and the repair and restoration of damaged ecosystems. As ecologists and restorationists, we may have to rethink much of what we had learned or assumed was steady, fixed, and certain about ecosystems or plant communities as climate change makes those systems increasingly unstable. Even though these changes may not occur for several decades, I think it is important to begin discussing their implications now, and to set in place experiments and take other measures that will help us answer the questions and problems that will face us and future generations.

Three ideas come to mind when thinking about the implications of climate change for the restoration community. First, I suggest, as did Robert Peters in his 1985 article, that restorationists, especially those in academia, conduct long-term experiments that attempt to create plant communities outside their "normal" range. For example, building plant communities in places hundreds of miles south of their current locations in order to determine the changes that take place due to longer periods of higher temperatures and drought conditions. This work could be done in the field, in the lab, and through computer modeling. In addition, managers and others should begin immediately to mon- itor existing natural areas and restoration sites for changes in vegetation composition and health. With these data sets in hand, researchers could then begin to tease out answers to some questions related to assembly theory: How does a species or guild react to climate change? How do they reassemble? What role will exotic and invasive species play in the new compositions? Will we have to rescue more and more species as climate reduces their habitat? Answers to questions such as these should help us better understand what this new world might look like and what our role as restorationists and managers might be. Ultimately, we will have to face the more philosophical question: Should we attempt to play gods in this situation or just trust that a new, sustainable biodiversity will emerge?

Second, policymakers and politicians at various levels of government around the world will increasingly seek ways to decrease greenhouse gas emissions as well as mitigate their effects. The most talked about mitigation measures are those that involve carbon sequestration. The U.S. Department of Energy and the U.S. Forest Service are studying the potential of oceans, forests, agricultural land (including grasslands), biomass plantings, arid lands and degraded lands, and boreal wetlands and peat bogs to sequester carbon. In Canada, analysis of the Prairie Farm Rehabilitation Administration's Permanent Cover Program-the counterpart to the Conservation Reserve Program in the United States-indicates that perennial grasslands sequester more carbon than annually-plowed croplands, and that planting perennial grasses on marginal croplands could help Canada meet its goal of mitigating greenhouse gas emissions. While both of these programs are laudable and could signal an economic boon to the restoration industry, I worry that monies for such efforts will downplay the need for diverse seed mixes and may require the conversion of some ecosystems - wetlands may be especially vulnerable because they do not fit the forest-minded scheme established in Kyoto-in favor of those systems that have recognized ability to sequester carbon. I think it is important that restorationists and land managers have a voice in these decisions and that we avail ourselves of the information necessary to make a cogent argument for maintaining and restoring a wide range of ecosystems.

Finally, I'd like to suggest that researchers study the role of prescribed burning and its possible effect on climate change. Burning of biomass produces aerosols (microscopic airborne particles) that tend to cool the the earth's surface because they have a negative effect on the amount of radiant energy that reaches the 
Earth. The scientific understanding of aerosols is surprisingly limited, however, when compared to what we know about the effects of greenhouse gases, such as carbon dioxide, methane, and nitrous oxide. Most of the knowledge about aerosols comes from work done on the effects of burning coal due to the problems with air quality and acid rain which that fossil fuel produces. Nevertheless, I am left to wonder: Could it be that the pre-Industrial world where burning of wood for heat and power as well as the burning of prairies and savannas for animal habitat, basketry, and safety provided a better balance between the forces that warm and cool the Earth? Could burning more grasslands and woodlands, in addition to other mitigation measures and technical fixes, help alleviate the trend toward a warmer world?
I think it goes without saying that restorationists should take this issue of climate change seriously, both in our personal and professional lives. We need to encourage and support technologies and government policies that will reduce greenhouse emissions. We must learn more about climate change and its effect on plant and animal communities. Moreover, we have to accept our civic responsibility and serve as advisors to government agencies working to mitigate the effects of greenhouse gas emissions. Whatever happens with the climate in the 21 st century, we are going to have remain flexible, while keeping our central tenet in mind - the restoration of degraded ecosystems.

Dave Egan 